\title{
Observed Mental Processing Patterns in Good EFL Listeners and Poor EFL Listeners
}

\author{
Ching-ning Chien \\ Department of Applied Linguistics and Language Studies, Chung Yuan Christian University, Zhongli, Taiwan \\ Nicholas Van Heyst \\ National Pingtung University of Science and Technology, Taiwan
}

\begin{abstract}
The purpose of this study aims to gain a better understanding of EFL learners' actual use of learning strategies in listening comprehension. One hundred and sixty-five sampled students from different disciplines participated in the study. They completed the whole process of survey and assessment, which included an MEPT English proficiency test, think-aloud protocol and immediate recall interviews. The study involved two groups which were distinguished based on listening comprehension scores from the MEPT; namely, those who scored greater than $\mathbf{7 0 \%}$ and those who scored lower than $50 \%$. By examining apparent differences in the strategies used by each group during the listening interpretation, the study found that even within these differences a common thread could be seen. There were three major commonalities that emerged as students worked to develop meaningful patterns from the listening content. A number of conclusions can be drawn from the data. First, good EFL listeners use more strategies than poor EFL listeners. Secondly, both groups appear to switch strategies at the point in which the one they were using fails to fulfill its purpose; however, the poor listeners gave up trying sooner. Thirdly, both groups appear to be using the available information to develop a discernible pattern. This study suggests that strategy use is not the most important factor that separates good listeners from poor listeners. Rather, failure to recognize audio linguistic clues and cultural scripts seem to be more important causes of comprehension failure.
\end{abstract}

Index Terms - mental processing, listening comprehension, learner strategy, EFL learners

\section{INTRODUCTION}

The English language has already become a very important tool for a great number of different cultures throughout the world and thus it is not uncommon for countries or individuals who speak different languages to choose English as their first foreign language (EFL) for acquisition. Taiwan is one such country, and our education institutions, both formal (public and private schools and universities) and informal ('cram schools'), spare no effort in trying to equip students with the English skills they need to use for communicative or research purposes. Unfortunately, despite the fact that Taiwanese students are often capable of learning vast amounts of written vocabulary, and may even be pretty good in written grammatical knowledge, they often show significant difficulty when it comes to listening comprehension in English as their second language (L2).

The ability of the human brain to ascribe different and specific meanings to innumerable distinct, similar and even sometimes identical sounds and tones is a wonder that may perhaps never be fully understood. There are so many different contributing factors that appear to be working (or failing to work) in harmony to allow listeners to create concrete meaning from the abstract sounds that fill their ears. A review of the literature on listening reveals a significant divergence in views about the process which is rooted in different theoretical assumptions of how human beings go about deriving meaning from a string of language signs and of those factors that are considered crucial for achieving comprehension. Approaches to listening comprehension which have been the most widely discussed may be grouped as the linguistic approach, the sociolinguistic approach, and the psycholinguistic approach. Although researchers who are keen on understanding this fascinating process have tried to look at it from all perspectives, there are still many questions that need to be answered. For example, what happens between the top-down and bottom-up processing of listening input to facilitate listening comprehension in EFL learners?

The present study

The purpose of this study is to try and gain a better understanding of what actual listening strategies were used in listening comprehension by EFL listeners. The study looked at two groups of listeners - poor EFL, and good EFL - to try and uncover answers to the questions posed here. These questions are: do good listeners always use more strategies than poor listeners? What effects does working memory have on strategy use? And how much does the cultural difference across the two languages affect listening comprehension?

\section{LiterATURE REVIEW}

A. Listening Comprehension Research: Top-down and Bottom-up Studies 
In the past decade, there has been an explosion of research articles describing the effect listening strategies may have on listening comprehension. Despite the fact that much of this research has been observational and argumentative, lacking either adequate controls or robust longitudinal data (Lee, 2010), many studies have still proclaimed the effectiveness and benefits of listening strategy instruction (Vandergrift \& Tafaghodtari, 2010). Though it is clear that more proficient listeners use more types of listening strategies, and use them more frequently than less proficient listeners; however, the exact causation of this phenomenon has not be conclusively determined (Vandergrift \& Tafaghodtari, 2010). Furthermore, most studies are oriented towards investigating either higher order, top-down processing (such as prediction, checking for understanding, and inferencing), or lower order, bottom-up processing (such as relying on morphology, syntax, prosody, segmentation, or semantic clues). Only a few studies, such as the one conducted by Lee and Cai (2010), have tried to analyze how these two aspects interact (Field, 2004). Graham et al. (2011), acknowledging that the mixing bowl into which the fruits of top-down processing and bottom-up processing are placed has not been adequately understood. It has been discovered that some learners may actually be at a greater disadvantage because of improper use of higher-order listening strategies when compared to learners that employed no higher-order listening strategies. These uncertainties demonstrate the fact that the mental models which listeners construct to ultimately decode the listening input need to be better understood.

\section{B. Working Memory Is a Crucial but Neglected Factor in Listening Comprehension}

With respect to the cognitive aspect of listening comprehension, Wolff (1983, p. 290) characterized it as "an active cognitive process, making use of linguistic knowledge (procedural), and knowledge of the world (declarative)." He also pointed out that "comprehension is not limited to perceiving sounds and sound patterns" but also includes an "interpretation of the speaker's intentions." Other research explains that cognitive processing represents brain activity in the neural system, in which a large number of neurons (or cells) encode abstract concepts and images as they are 'fired' or activated by the visual or auditory stimuli and bring out a meaningful interpretation (Anderson, 2005; Blakemore \& Frith, 2005). Consequently, these processes, by default, have the ability to affect a person's listening comprehension. This can help to explain why, even when a listener has the desire to listen, and is trying to focus, there are certain cognitive processes that can potentially override the efforts of the listener. Thus, this newly developing field of neurolinguistics, borrowing heavily from the mature discipline of cognitive psychology, has shown the clear need to reconceptualize our static and serial models of language decoding, including listening comprehension (Wen, 2012). These "active processes" when in play, will naturally function best when the least amount of strain is applied to them, a fact that could be tied to the notion that higher-order listening strategies potentially hinder listeners, or that familiarity benefits them. However, as the abovementioned quote from Wolff implies, there is a fundamental precondition that linguistic knowledge exists. Listening strategies may help with this process by reducing strain; they may also hinder this process by adding strain. The same might be true for cultural differences/similarities.

\section{Cultural Differences on L2 Listening Comprehension}

Cultural differences have the potential to affect a person's listening comprehension ability in a number of ways. For instance, Bouton $(1988,1992)$ looked at the relationship between culture and the ability for listeners to understand the meaning of a speaker's implications. His studies showed significant differences in understanding between native and nonnative listeners, supporting the idea that cultural familiarity plays an important role in listening competency. More specifically, Min Deok-gi (1996) focused on topic familiarity, and showed that students who had greater familiarity with a topic were able to score higher on questions that focused on explicit items. Wierzbicka (1994) made an argument that understanding different languages often requires knowledge of certain "scripts" that are built into a specific culture; these scripts could be described as a "shared set of subconscious cultural norms that carry meaning." In her study (1994), she made a comparison of common Japanese and American scripts to emphasize the difference in the way that people from one culture may misunderstand a speaker belonging to the other culture despite having adequate linguistic understanding. Cultural differences can also be manifested on the cognitive level as Nisbett, et al. (2001) demonstrated when they showed that cognitive differences between Eastern and Western cultures were based on holistic and analytic approaches respectively. Markham (2000) looked at the religious aspect of culture and showed that both religious background knowledge and captions were able to contribute substantially to ESL student's listening comprehension. And more recently, a study by Hayati (2009) conducted on Iranian EFL students demonstrated that students with increased understanding of the target culture performed better on listening exercises. Based upon this research it is fair to assume that perceived cultural differences, generally speaking, have the ability to affect how competently a listener is able to understand second/foreign language listening content. Of course, such an understanding also leads to a number of avenues that need to be explored to help gain further insight into what can be done to help L2 listeners improve their listening skills.

\section{METHOD}

\section{A. Participants}

One hundred and sixty-five Taiwanese students of different majors participated in the study in the academic years 2010 and 2011. 96.1\% were freshman students at the time of sampling and came from different majors, including 
Applied Linguistics, Chemistry, Electrical Engineering, International Trade, Chemical Engineering, Information Management, and Psychology. The study targeted two groups of students. Group 1 is comprised of students who scored $70 \%$ or above correct in listening, grammar and vocabulary on the Michigan English Placement Test (MEPT). Group 2 is made up of students who are good at vocabulary and grammar, but poor at listening comprehension based on scoring $70 \%$ or above correct in grammar and vocabulary, but less than $50 \%$ correct in listening on the MEPT. Group 1 totaled 69 students and Group 2 totaled 96 students. The academic majors comprising Groups 1 and 2 can be seen in Table 1, below.

TABLE 1.

DISTRIBUTION OF ACADEMIC MAJORS FOR STUDENTS IN GROUPS 1 AND 2.

\begin{tabular}{|l|l|l|l|l|l|l|l|}
\hline & $\begin{array}{l}\text { Applied } \\
\text { Linguistics }\end{array}$ & Psychology & Chemistry & $\begin{array}{l}\text { Intl. } \\
\text { Trade }\end{array}$ & $\begin{array}{l}\text { Electrical } \\
\text { Engineering }\end{array}$ & $\begin{array}{l}\text { Info. } \\
\text { Mgmt. }\end{array}$ & $\begin{array}{l}\text { Others } \\
\text { Total }\end{array}$ \\
\hline Group 1+2 & 19 & 23 & 16 & 39 & 34 & 4 & 30 \\
\hline $\begin{array}{l}\text { Group 1 } \\
\text { good overall) }\end{array}$ & 12 & 2 & 4 & 11 & 13 & 0 & 27 \\
\hline $\begin{array}{l}\text { Group 2 } \\
\text { (poor listeners) }\end{array}$ & 7 & 21 & 12 & 28 & 21 & 69 & 4 \\
\hline
\end{tabular}

\section{B. Data Collection}

The data collection was conducted in a language lab classroom which has 64 carrels, each equipped with an audio recording device, earphones, and a microphone (the CYCU language lab is a very well-equipped exam room and has been used as the testing room during the Taiwan General English Proficiency Test for participants who live in the area of Taoyuan County, Taiwan). In the first week of the first semester, the participants were given the Michigan English Placement Test (MEPT); in the second week, after the researcher finished explaining the procedures and completing a practice warm-up, the participants were administered a think-aloud protocol on two listening tasks (one is a conversation and the other is a short news piece). At the completion of each listening task, participants were also asked to recall their thoughts by answering 12 questions. The immediate recall was intended to allow participants to do their self-report retrospectively, and the questions were designed to help elicit their mental processing. The researcher and the research assistant sat at the laboratory control desk, controlling the playback for each listening task and the time allowed answering the recall questions. Although the listening tasks were all in the L2 (English), participants were permitted to complete the think aloud and the recall in their L1 (Chinese). Afterwards, all participant audio recordings were transcribed for analysis.

\section{Selected Materials for the Immediate Protocol Recall on the Listening Tasks}

Four genres of listening materials, which include story, conversation, lecture and news, were used to elicit students' listening strategies. The language used in the scripts is natural and authentic. The difficulty level in terms of vocabulary and grammar knowledge, topical familiarity and cultural familiarity were taken into consideration (see Table 2). The length of each script is one to three minutes.

TABLE 2.

LISTENING MATERIALS USED IN THE PROJECT.

\begin{tabular}{|l|l|l|l|l|}
\hline Genre / Description & Conversation & News & Story & Lecture \\
\hline $\begin{array}{l}\text { Language difficulty level-- } \\
\text { vocabulary }\end{array}$ & Intermediate & High- intermediate & Intermediate \\
\hline $\begin{array}{l}\text { Language difficulty level-- } \\
\text { grammar }\end{array}$ & Elementary & High- intermediate & Intermediate & High- intermediate \\
\hline Topical familiarity & Unfamiliar & Unfamiliar & Unfamiliar & Unfamiliar \\
\hline Cultural familiarity & Partially unfamiliar & Mostly unfamiliar & Partially unfamiliar & Mostly unfamiliar \\
\hline
\end{tabular}

The four listening tasks played for each of the participants were intended to cover a range of listening experiences that most English speakers are likely be exposed to from time to time. They included a real life event, a news report, a short story, and a speech. The first listening task that was played for the participants was a dramatization of attempting to return an item that was purchased from a store. The second listening task made use of a news recording from the $\mathrm{BBC}$ reporting on the reaction of the Polish people to the tragic plane crash that took the lives of a number of the Polish government officials in 2010. Like with most news broadcasts, the information presented does not deal with typical life events and the rate at which the reporter speaks is faster than normal conversation. Furthermore, the news reporter speaks with a British accent and the interviewees spoke with Polish accents. The third listening task consisted of a children's story. The story was a moral tale centered on a conversation between a father beaver and a son beaver, where the father tries to teach the son the importance of putting work before play. Since this was a children's story, the vocabulary heard in this recording was well within the bounds of what most young children between the ages of 7 and 10 years old would be familiar with. The fourth and final listening task was a recording of a portion of an inspirational speech. The speech given was a typical example of what one can often hear at a graduation ceremony, and had the basic theme of "making the most of one's life". Throughout the speech, a significant number of clichés were used or 
referenced. These clichés are ones that most native English speakers growing up in North America would be expected to be familiar with by the time they were in their early teens.

\section{Think Aloud Protocols and Immediate Recalls}

In order to catch a glimpse into the minds of the subjects who took part in the study, the listeners were asked to report all of their thoughts in real time as they listened to the selected recordings. The real time reporting allowed the researchers to not only assess the listeners' understanding of the listening task, but also helped to provide some insight into the strategies that each of the subjects used to try to develop a full understanding of the recordings that were played for them. The participants were asked to vocalize their thoughts, which were recorded on a recording device to allow for in-depth analysis. In addition to the real-time thought reporting, an immediate recall was also administered whereby subjects were asked a series of 12 questions after each of the listening tasks (Appendix A).

\section{ANALYSIS AND RESULTS}

Two sets of collected data were analyzed: (1) participants' think aloud protocols in the four L2 listening tasks and their self-report on recalls to find their actual use of listening strategies and (2) cultural scripts identified in the testing material.

By generalizing the think aloud and the immediate recall, it is clear that students from both groups made use of listening strategies when listening to the selected recordings. No matter if they were good listeners or poor listeners, a pattern emerged suggesting that in each of the cases the listener would begin the listening task by making use of a strategy that would expend the least amount of mental energy needed to achieve the desired results; in other words, consume the least working memory. In all cases, students began the exercise by "focusing their attention" to the task or "elevating their level of concentration". To highlight the relevance of this strategy, it can be pointed out that at the commencement of casual conversation between friends or family members this increased level of concentration often would not be present; whereas, when listeners are aware that they are listening for a specific purpose or goal they will tend to use more selective attention (Graham et al., 2010). The reason a greater attention was present at the beginning can be explained by the fact that the subjects likely anticipated that because it was a listening comprehension study, they would likely face certain challenges. In the event that they met difficulties they would then move to adopt an alternative listening technique that would hopefully allow them to construct a workable pattern. The most prevalent secondary listening technique was the one in which the cultural aspect could be seen. This technique, generally speaking, could be described as 'inference making.'

\section{A. Observed Patterns from the Think-aloud Protocol and Immediate Recalls: Good EFL Listeners vs. Poor EFL Listeners}

The results revealed that an overwhelming majority of both groups had made use of listening strategies during the listening tasks. This section will analyze the trends that were discovered. Somewhat surprisingly there was a very high number of shared listening strategies seen in both groups. However, there was also a number of apparent differences that could be identified.

\section{Analysis of similarities between Group 1 and Group 2}

Both the good listeners and the poor listeners began by making an effort to concentrate on the listening content. Concentration, of course, is a fundamental factor in listening regardless of the level of the listeners' ability. However, it is worth noting that the poor listeners also made the effort to direct their concentration towards the listening task so that the possibility that their poor comprehension was a result of their failure to focus can be ruled out.

Throughout the listening tasks, both groups also made efforts to associate the audio with the images that were displayed on the computer screen (if they were available) and to pay attention to the tone of the speaker. Students from both groups also located what they determined to be key words and often made notes on a piece of paper. Other common strategies that were used by members of both groups include making inferences based on context, past experiences, and previous knowledge. The use of this strategy is similar in many ways to the strategy of associating the audio with the visual imagery mentioned above.

\section{Analysis of differences between Group 1 and Group 2}

The results show that the good listeners tended to use more listening strategies than the poor listeners and also changed strategies more frequently. It should be noted that the changing of strategies is more than likely the result of the strategy failing to work; the good listeners keep trying by using another strategy while the poor listeners stop trying early.

Also related to the abovementioned difference, another variation that was noted was that the good listeners focused on the areas they missed and tried to fill in the gaps, while the poor listeners tended to focus more on what they knew and choose not to try and understand more.

\subsection{Similarities within the differences}

Both groups used what they knew.

By taking a closer look at what appeared to be differences in the strategies that each of the two different groups used during the listening tasks, it became evident that even within these differences a common thread could be seen. The first 
commonality was that both groups of listeners made use of what they knew already to try and build greater understanding. That is to say, the listeners both believe (unconsciously, of course) that reaching understanding will depend on whether or not they can connect enough 'dots' together; and once enough dots have been connected a meaning can be formed. 'Pattern seeking' is perhaps an appropriate description of what is taking place, and it is probably safe to say that every interlocutor of any skill level is making use of this method when they try to form meaning based on the information that is provided to them from the other party.

Both groups change strategies when methods strategies fail

The second commonality that was seen was that both groups would switch to another strategy once they felt as though the previous strategy was not satisfying the goal. It is quite easy to recognize that this is very much related to the 'pattern seeking' mentioned above. Simply stated, when no pattern begins to form, the listener finds an alternative means to locate a pattern. Based on considerations of human nature, it is probably a safe guess that the listener will always make use of the 'easiest' method available to attain their goal of determining the pattern. For instance, if the listener cannot determine a pattern simply by "just concentrating," he or she may start feeding on other sources of information and begin the process of making inferences. This was the second commonality witnessed in the study.

\section{Both groups are making inferences}

The third commonality was that both groups significantly used the strategy of inference albeit in different ways. One of the differences in the way the groups used inference is how easily they implemented the tactic and the duration for which they used it. This observation may be related to the fact that inferencing demands more of the listener's mental energy and therefore will also result in the more rapid arrival of the moment in which the listener decides to give up on the strategy altogether.

\section{Both groups act out their emotions}

The fourth commonality is not so much an intellectual factor, rather, it is more of an emotional one. That is to say, the behavior of both groups appears to be influenced by affections, i.e., something similar to pride or humility. Initially, it appears that all listeners make the effort to try to understand the listening content; they begin with the notion that it is something that they are capable of accomplishing. For those who experience some level of success, their desire to 'tackle' the difficulty will drive them to spend additional energy on hopes of reaching their goal. These participants are humbled by the difficult nature of the task and they are mindful of the amount of effort required to reach their goal. However, those who quickly succumb to the task and accept defeat, appear to act indifferently, make jokes, complain, or sleep as a means of distancing themselves from the activity. In other words, "better" students might humbly think that learning a language is difficult so they keep on trying, knowing that it is not easy, and "worse" students who appear reckless might think that they do not care much for learning a language. It would be interesting to have a deeper understanding of EFL learner/listeners' affective and emotional state during the comprehension process for our future study.

\section{B. Identified Misunderstanding of the Cultural Scripts in the Four Listening Texts}

Culture can be defined as the integrated system of learned patterns of behaviors, ideas, and products, which are characteristic of a society. That is, culture is the patterns of living that people have learned from all other persons around them. Cultures can be different from country to country or from place to place; therefore, misinterpretations or misunderstandings can easily take place when people use patterns or assumptions from their home culture to interpret what they are listening or reading in a foreign language.

To identify the cultural scripts, the researchers first chose the words, phrases or sentences related to cultural ideas from the four listening tasks. A calculation was then made on the percentage of misunderstanding for the words, phrases or sentences related to cultural ideas for both the good and poor listeners. The results indicated that poor listeners had a higher misunderstanding percentage (71.2) than good listeners (55.2), shown in Table 3. However, even the good listeners could not catch the ideas up to $55.2 \%$ of the time.

TABLE 3.

PERCENTAGE OF MISUNDERSTANDING OR MISINTERPRETATION IN THE CULTURAL SCRIPTS: GOOD LISTENERS AND POOR LISTENERS

\begin{tabular}{|l|l|l|l|}
\hline Four listening tasks & cultural scripts & $\begin{array}{l}\text { Percentage good listeners } \\
\text { missed }\end{array}$ & $\begin{array}{l}\text { Percentage poor listeners } \\
\text { missed }\end{array}$ \\
\hline conversation & $\begin{array}{l}\text { restocking fee; } \\
\text { policy; } \\
\text { dispute charge; } \\
\text { credit card company }\end{array}$ & $17.6 \%$ & $36.6 \%$ \\
\hline news & $\begin{array}{l}\text { Easter; } \\
\text { Prime Minister }\end{array}$ & $68.3 \%$ & $82.0 \%$ \\
\hline speech & $\begin{array}{l}\text { it is not the things we do in life } \\
\text { that we regret on our death bed, } \\
\text { it is the things we do not; } \\
\text { and that's where my solace } \\
\text { comes from }\end{array}$ & $79.6 \%$ & $94.9 \%$ \\
\hline Total & & $55.2 \%$ & $71.2 \%$ \\
\hline
\end{tabular}




\section{CONCLUSION}

According to the data collected in this study, a number of conclusions may be drawn. First, this study confirms what has been seen in other studies, that good ESL listeners use more strategies than poor ESL listeners. All ESL listeners also appear to switch strategies at the point in which the one they were using fails to fulfill its purpose. However, the poor listeners give up trying earlier.

Based on this study it is evident that good ESL listeners and poor ESL listeners both use the same listening strategies. Both groups appear to be using the available information to develop a discernible pattern. Both groups changed listening strategies when difficulties arose. However, it is not clear what the cause and effect relationship between good listeners and strategy use is.

As mentioned above, both good ESL listeners and poor ESL listeners appear to change strategy at the time in which he or she finds that the previous strategy was not working. A logical conclusion that can be derived from this is that if the listening strategy employed allows the listeners to maintain their desired level of understanding, they will not have to transfer to other strategies. In order to confirm whether or not this is in fact what is taking place, more research must be conducted.

Based on this study, strategy use plays an important part in the listening process and therefore does deserve its fair share of classroom attention, however this study suggests that strategy use is not the most important factor that separates good listeners from poor listeners. Rather, failure to recognize audio linguistic clues and cultural scripts seem to be the two areas that lead to comprehension failure. Many language teachers across the world have not yet had training in listening instruction pedagogy and this may be due to the lack of clear direction within the field (Graham et al., 2010).

\section{APPENDIX A}

\section{Post-listening interview questions:}

1. What was the first thing that you did in order to make sense of this?

2. Did you do anything else to help you understand at any point in the listening?

3. At any point in the listening did you change your mind as to what this was about, or what to listen for?

4. What can you remember hearing?

5. Can you remember anything else that you heard?

6. Do you remember learning anything new? Any new information?

7. Do you remember hearing anything else?

8. Any new words (unfamiliar words)?

9. On a scale of 1-10, how confident are you that you understood this passage?

10. On a scale of $1-10$, how much did you understand this passage?

11. What do you think about the difficulty level of the sentences you heard?

12. Are you familiar with the content of the listening task? How much did you already know about this topic?

\section{ACKNOWLEDGEMENT}

This work was supported by the National Science Council, Taiwan, ROC [grant number NSC100-2410-H-033-027]

\section{REFERENCES}

[1] Anderson, J. R. (2005). Cognitive psychology and its implications (6th ed.). NY: Worth Publishers.

[2] Blakemore, S. J. \& Frith U. (2005). The learning brain: Lessons for education. England: Blackwell Publishing.

[3] Bouton, L. F. (1988). A cross-cultural study of the ability to interpret implicatures in English. World Englishes, 7(2), 183-196.

[4] Bouton, L. F. (1992). Culture, pragmatics, and implicature. In H. Nyyssonen \& L. Kuure (Eds.), Acquisition of language Acquisition of culture (pp. 35-61). Jycaskyla, Finland: AFinLA.

[5] Field, J. (2004). An insight into listeners' problems: too much bottom-up or too much top-down? System, 32(3), 363-377.

[6] Graham, S., Santos, D., \& Vanderplank, R. (2010). Strategy clusters and sources of knowledge in French L2 listening comprehension. Innovation in Language Learning and Teaching, 4(1), 1-20.

[7] Graham, S., Santos, D., \& Vanderplank, R. (2011). Exploring the relationship between listening development and strategy use. Language Teaching Research, 15(4), 435-456.

[8] Hayati, A. M. (2009). The Impact of Cultural Knowledge on Listening Comprehension of EFL Learners. English Language Teaching 2(3), 144-152. Retrieved from_http://www.ccsenet.org/journal/index.php/elt/article/view/3704/3305.

[9] Lee, O. (2010). Remaining Issues In metacognitive instruction for second or foreign language listening development. $S N U$ Foreign Lang. Res. J., 76(6), 25-45.

[10] Lee, B. P. H., \& Cai, W. (2010). The effects of language proficiency on unfamiliar word processing in listening comprehension. Hong Kong Journal of Applied Linguistics, 12(2), 61-82.

[11] Markham, P. (2000). The influence of culture-specific background knowledge and captions on second language comprehension, Journal of Educational Technology System, 29(4), 331-343.

[12] Min, D. (1996). The effects of topic familiarity, pre-listening activity, and question type on Korean junior-high school students' listening comprehension (Doctoral dissertation, The Pennsylvania State University, 1996). Dissertation Abstracts International, $57-12,5087$. 
[13] Nisbett, R. E., Peng, K., Choi, I., \& Norezayan, A. (2001). Culture and systems of thought: Holistic versus analytic Cognition, Psychological Review, 108(2), 291-310.

[14] Vandergrift, L., \& Tafaghodtari, M. H. (2010). Teaching L2 learners how to listen does make a difference: An empirical study. Language Learning, 60(2), 470-497.

[15] Wen, Z. (2012). Working memory and second language learning. International Journal of Applied Linguistics, 22(1), 1-22.

[16] Wierzbicka, A. (1994). "Cultural scripts": A semantic approach to cultural analysis and cross-cultural communication. Pragmatics and Language Learning, 5,1-24.

[17] Wolff, D. (1983). Überlegungen zum Hörverstehen im Fremdsprachenunterricht (Thoughts on Listening Comprehension in Foreign-Language Instruction). Die Neueren Sprachen, 82(4), 282-297.

Ching-ning Chien holds M.A. degrees in Special Education from Tennessee Technological University and in English Education from Ohio State University, as well as a Ph.D. degree in Education from the University of Newcastle upon Tyne, England. She is currently an associate professor in Applied Linguistics at Chung Yuan Christian University where she teaches listening, speaking and reading to freshman students. Her research interests include foreign language listening comprehension, foreign language learning and teaching, bilingualism, phonological awareness and second language acquisition.

Nicholas Van Heyst currently works as a translator and part-time English teacher for National Pingtung University of Science and Technology, Taiwan. In 2009 he earned his bachelor's degree in Pacific and Asian Studies from the University of Victoria, Canada and in January 2013 was awarded his Master of Law degree from Chung Yuan Christian University, Taiwan. During his master's studies he worked for Dr. Ching-ning Chien as a research assistant in the field of Applied Linguistics and ESL. He has also worked with the Taiwan Ministry of Education, Elite Study-in-Taiwan Office as a translator and editor. 